\title{
Current Situation and Countermeasures of Volleyball Teaching in Regular Universities
}

\author{
Qi-lin $\mathrm{Hu}$, Li Chen, Yue-ming Duan, Yan-jun Wang \\ Dept. of P.E. Wuhan University of Technology, Wuhan China \\ E-mail: hh1970@126.com
}

\begin{abstract}
Since 2004's Olympic Games, volleyball in China drops into a low point once again. One of the factors causing the situation is the ineffective development of the volleyball in colleges and universities. By investigating and analyzing the development of volleyball teaching and extracurricular activities in regular colleges and universities, the difficulties for volleyball's development in colleges and universities are attempted to be found and the corresponding countermeasures will be presented. At the same time, providing reference for improving the quality of volleyball teaching in colleges and universities, it affords theoretical foundations for the Department of Education and the Department of Sports to formulate the relevant policies.
\end{abstract}

Keywords-volleyba; regular universities; motivation; reflection

In 2010, men and women's volleyball teams of China both fell into the dumps. In the new Olympic cycle, they achieved the worst results for the past 36 years. Sooner, in the June of the following year, the Chinese Women's Volleyball Team was completely defeated by the Japanese Volleyball Team with a score of 0-3 during the grand prix of women's volleyball in Switzerland. [1] Although Chinese women's volleyball players outclass the Japanese players on height, physical quality etc., they lost the game with an unimaginable score. Regardless volitional quality is one of the essential factors; the increasingly weakened mass base of Chinese volleyball is also an indisputable fact. As undergraduates are the hard core of the physical culture and sports, college sports bear a significant role on enhancing the athletic skills of university students and promoting their good development in both body and mind. As a result, mass participation of college students becomes one crucial way of volleyball's development and improvement. By investigating and analyzing the current situation of volleyball teaching in regular colleges and universities, the problems for volleyball's development in colleges and universities will be discovered and the corresponding countermeasures will be presented. Meanwhile, the basis for the Department of Education and the Department of Sports to formulate the relevant policies is provided.

\section{OBJECT OF STUDY AND METHODOLOGY}

\section{A. Object of Study}

Our second grade students who enroll in the volleyball elective course 362 .

\section{B. Methodology of Study}

a. Method of Literature and Documentation

Refer to the research papers and the materials of education science, psychology and so forth on the China National Knowledge Infrastructure (CNKI). Log in websites of the School of Physical Education of some colleges. Understand the situation which the universities start the volleyball course and lay a foundation for the research and analysis of the study.

b. Interviewing Method

Interviewing the relevant experts and the PE teachers, on the basis of their opinions and advices, the research contents are determined and the questionnaire is formulated. Interviewing the students enroll in the volleyball classes, cognition degree of the students for the volleyball and the suggestions for establishing the volleyball course are understood in order to offer counsel for the development of volleyball teaching.

c. Questionnaire Method

Make the questionnaires and give out to the students of the volleyball courses. Under the guidance of the course teacher, the students should complete the questionnaire independently at the site according to the requirement. Altogether 362 pieces of questionnaire are handed out and the retrieving questionnaires are 362 ; the recovery rate is $100 \%$, including 362 valid pieces and the effective rate is $100 \%$.

d. Logical Analysis

On the basis of the questionnaire filled out by the students and the interviews with them, by applying the logical analysis to summarize and organize, the present issues are found in the volleyball teaching and the counter measurements are proposed.

e. Mathematical Statistics

The regular statistical treatment is conducted to the data obtained in the questionnaire survey.

\section{RESULTS AND ANALYSIS}

\section{A. Volleyball Court of the School and the Present Situation of the Teachers of the Elective Volleyball Course Abbreviations and Acronyms}

The enrolled students of our school are approximately 45,000 ; there are two gymnasiums to carry through volleyball games and eleven outdoor volleyball courts. The covered area is $3,168 \mathrm{~m}^{2}, 0.07 \mathrm{~m}^{2}$ per each student. Obviously, the ratio is quite low. The volleyball courts at 
the school are insufficient. The far distance from the students' dormitories are another element affecting the students participate less in the volleyball exercises. Furthermore, cold winters, hot summers and the moist rainy seasons also block the students from joining in the volleyball sports.

The quantity and the quality of the teaching staff are the key to enhance the level of volleyball teaching. The department of sports of our school possesses 102 physical education teachers in total, including 11 special volleyball teachers which occupying $10.8 \%$ of the total number of teachers. The ratio, the special volleyball teachers out of the total number of teachers, is proper. The structure of the gender, education background and professional title basically tend to be reasonable, but none of the volleyball teachers are under 35 . The lack of young teachers causes the deficiency of various age groups, which leads to the insufficient energy of the volleyball teaching. This might be related to the onesided demand for high academic qualifications of teachers in universities. Because of fewer students select volleyball classes, part of the volleyball special teachers turn to table tennis, tennis and other sport events. The overall number of the elective volleyball teachers is 6 . Also, the teachers of the elective volleyball course for each academic year are around 4.

\section{B. Survey and Analysis of the Situation Which the Students Understand the Volleyball}

Cognition and understanding of one sport event are the important conditions of being fond and participating in the sport. The sport event which is loved to be heard and seen by people attracts more participators. Mutually people influence and encourage each other, as the interests for the sport and the enthusiasm of the participatory gradually are increased. At the same time, the mass base is strengthened. By means of the survey of the situation of students' understanding and cognition of volleyball, the development of volleyball in primary and secondary schools is analyzed. We could tell that the students who received the survey at their primary and secondary level studies all fundamentally understand the volleyball. It directly draws linkage to the brilliant ear created by the Chinese Women's Volleyball Team in 1980s and also relates to the golden metal of the 2004's Olympic Games. However, the situation of volleyball classes established in primary and secondary schools is unhopeful. Only 5\% primary schools, $10 \%$ junior high schools and $20 \%$ senior high schools start the volleyball classes. As a result, the situation of the volleyball classes starting in primary and secondary schools are unoptimistic. The active participation in volleyball exercise mostly starts from colleges. At the secondary school level, due to the pressure of entering a higher school level, the schools and the parents are not pleased with the fact that the students spend more time on the playgrounds, directly causing the weakening mass bass of the Chinese volleyball sport and the serious shortage of the reserve force. The supply mode of pyramid loses its own balance. This is an additional reason why both of the Chinese Men and Women's Volleyball Teams perform badly in the recent years.

\section{Analysis of the Motivation That the Students Take Volleyball Courses}

Motivation is triggered by the specific needs. Satisfying the special psychological state and aspiration of various needs are the internal reasons to encourage people to act. Favorable motivation should generate favorable effects, and favorable learning motivation is the prerequisite to master the knowledge and skills [2]. The survey of our school's students who take volleyball classes show that the motivations for them to participate in the volleyball events are mainly divided into four categories: seeking knowledge, bodybuilding, examinations and credits, and passive mode. The survey reveals: there are only 58 students take the class in order to improve the basic theoretical knowledge and skills, body fitness and actively participating in the volleyball classes, $16 \%$ of the total students who select the volleyball class. This part of the students mainly is from Guangdong, Guangxi and Hainan provinces, illustrating that Guangdong and Guangxi are the best areas with excellent mass base in China. 18\% students are actually interested in volleyball and are willing to work out their body and grasp a method for life long exercise. Those students mainly stay in fitness and have athletic abilities. $25 \%$ of the students take the class for dealing with the exams and earning credits. Most of the students in this portion have to select the course in order to graduate; otherwise they may face make-up examinations, repetition of the year and even dropping out. The passive learning students occupy $37 \%$, mainly manifesting that group psychology, no other choices and no clear learning motivations. The students in the later two categories normally have bad physical fitness, superficial sports consciousness and weak athletic abilities that lack of active participation abilities in exercise.

\section{Media for the Students to Know Volleyball and Focus of the Domestic and International Volleyball Events}

As the society develops rapidly, the forms of mass media have more diversity and the various media and modes are under huge transformation. Mass media is the crucial way for the students to understand sports, and the key agent of active participation in sports. It affects the formation of the students' values on sports and the learning of ways of exercises. To a certain extent, it stimulates the interests of participating in sports related activities and forms a healthy life style [3]. From the surveys of the ways for students to know volleyball and focus on the domestic and international volleyball competitions, it is obvious that the contemporary university students knowing sports and volleyball mainly through internet, occupying $48.1 \%$. In the second place, there are television media and newspapers where broadcast and magazines only occupy around $4.2 \%$, and it is almost negligible. These data displays the powerful function of computer networks due to its strong visual impact and speedy update rate of the information. Therefore, internet is the top choice for students to know sports and learn sports related knowledge. By the way, high owning rate of computers in students also provides condition for the wide range usage of computers. Through internet, students watch online live broadcast, sports news, competitions and 
browsing the websites about the study of physical education specialty. Moreover, the rate of the university dormitory equipped with televisions is low. This is another important factor which the students can not choose televisions to watch the live broadcasting games.

Due to the demonstrations of the individuality, the graceful movement, and the spirit of solidarity and cooperation, striving and activeness of the athletes, the sports events draw much attention of the world and have outstanding advantages. Enjoying the sports events cultivate the sense of competition for the students and the team cohesiveness, benefit for the students to set up right view of life and of world and assist to form good sports consciousness and habits of active exercise [4]. Through the survey of the students who focus on the domestic and international volleyball events, it is concluded that most of the college students pay close attention to the crucial international events of women's volleyball, such as Olympic Games and World Championships, and pay less attention to the domestic competitions, such as domestic volleyball league games and invitational tournaments. The reason is because the women's volleyball team has achieved brilliant successes in the history, the students still wish the Chinese Women's Volleyball Team can return to the top of the world and obtain honor for our country again. While the domestic volleyball league games due to the operation of the event, the television relay and many other reasons, the Chinese volleyball market stays gloomy so it is hard to attract students' attention.

\section{E. Survey and Analysis of the Students Who Participate in Volleyball After School}

The association of single sport event for university students is the significant organization for students to promote, plan, and develop extracurricular sports activities and events and it is the hard core of the single sport event in school, taking on responsibilities of absorbing and training sports activists and passing on the fundamental technique and tactics. Participating in the after school activities organized by the volleyball association is also the important way for the students who take volleyball classes to practice volleyball after class, strengthen and improve the basic technique and tactics of volleyball, enhance the actual practice abilities of students, cultivate the sense of competition and group work, encourage the activeness of practicing volleyball and effectively increase the quality of volleyball teaching. From the survey of the students who select volleyball class participating in the after school activities organized by the volleyball association, it shows the students who often participate are evidently few. $77 \%$ of the students never participate in the after school activities of the association, depicting that the students are not interested in volleyball, lack of activeness and never truly feel the charm of volleyball.

Students joining in the after school volleyball activities are mostly roommates or classmates. Participating with friends occupies $13 \%$ of all. Because the volleyball association establishes their own website and QQ group to benefit the volleyball friends for mutual communications and posting the relevant information, $51 \%$ choose to participate in the activities with their net friends. Nevertheless, individual who actively participating in the volleyball activities is only about $4.8 \%$. Thus, peer influence is one of the essential elements for the development of volleyball in colleges and universities. The training of the volleyball talents with basic skills should be enhanced. From the points covering the face, influencing the enthusiasm of the roommates and classmates towards volleyball, and increasing their activeness of participating in volleyball exercise, the population of volleyball "players" will be extended step by step.

\section{F. Analysis of the Students' Attitudes towards the Instruction After Class of the Volleyball Teachers}

Instruction after class is the extension of a sport class. It is the key method for students to improve their skills. Also, it reveals the care of the physical education teachers to the students, building up emotional relationship between teachers and students. Meanwhile, it increases the students' interests about volleyball and cultivates their habits of exercise after school in order to lay a foundation for a life long sports habit. Table 1 is the result of the survey about students' attitudes towards the instruction after class of the volleyball teachers. $86.7 \%$ of the students hope the volleyball class teachers participate in the after school instructions or hope it to happen very much. If the teachers often join in the activities of the volleyball association, the needs of students will be leant through the activities. With the coach of the physical education teachers, students' practices are always full of life. At the same time, the teachers' participation stimulates students to learn and exercise positively and actively and the number of students who join in the actives will be increased. Due to some teachers could not participate in the after school activities of students because of family, job, payment and other reasons, the development of volleyball is affected in certain extent.

Table 1: Survey about Students' Attitudes towards the Instruction after Class of the Volleyball Teachers

\begin{tabular}{cccccc}
\hline & Very & & & & Very \\
& Willing & Willing & Average & Unwilling & Unwilling \\
\hline Number & 183 & 131 & 33 & 15 & 0 \\
$(\%)$ & 50.5 & 36.2 & 9.2 & 4.1 & 0 \\
\hline
\end{tabular}

\section{G. Survey and Analysis of the Reasons Why Students Do Not Like Volleyball}

Interests are the positive mentality tendency to strive for cognizing matters and to long for seeking truth, linking to definite emotion and attitudes. It gives the people ability to preferentially pay attention to certain matters [5]. Interests are the premise of learning knowledge and one crucial way to obtain satisfaction of society. By investigating the elements why students do not like volleyball (See Table 2), it 
demonstrates that most of the students fear of the difficulties of grasping volleyball skills, such as easy to hit away the ball and pick up the volleyball everywhere; volleyball is too hard to get hurt; additionally, some students think comparing to basketball and soccer, volleyball is shortened of rivalry and intensity; therefore, it is difficult for them to be interested in. Thus, in the volleyball teaching, teachers should properly lower the difficulties of volleyball movements and allow mild holding and double hit. Next, appropriately lowering the height of the net, allowing more than six people in the inclass tournaments, undivided positioning of rows, and hitting the volleyball more than three times, the game continuing unless the volleyball falls on the ground, improving the students' hitting time and ball returning, increasing the ball control time for students are applied to enhance and extend the continuity of volleyball games and to increase students' learning initiatives.

Table 2: Survey of the Reasons Why Students Do Not Like Volleyball

\begin{tabular}{ccccccc}
\hline & Difficult Skills & Psychological Fear & Lack of Rivalry & Less Amount of Exercise & Few Participators & Other \\
\hline Number & 47 & 21 & 66 & 35 & 22 & 11 \\
$(\%)$ & 23.3 & 10.4 & 32.7 & 17.3 & 10.9 & 5.4 \\
\hline
\end{tabular}

\section{CONCLUSION}

The teacher resources of our school are reasonably equipped, forming a bond of all aged teachers with the assisting mode, but insufficient young teachers block the volleyball development in the university. The brilliant history of Chinese volleyball is influential to the young students and students actively participating in volleyball mostly occur in college days. Due to the study pressure, the secondary school students lack exercises. The total number of people who choose volleyball is low and falls far behind the other ball games. Numbers of students who actively and passively choose volleyball course are equal. Through internet, students know and understand volleyball, watching volleyball games by internet and television, and mostly women's games. Students who often participate in the activities of volleyball association are few and the participating ways are mainly with roommates and classmates. Students are willing to receive after school instructions of their teachers, increasing the activeness of the students at the same time. Disliking volleyball of the students is caused by the low cognition; therefore, the promotion of volleyball needs to be improved.

\section{ADVICE}

Under the organization and coach of the volleyball teachers and full function of the volleyball association of students, the backbone of volleyball talents should be cultivated and the interests of the students to participate in volleyball should be improved. Regularly holding volleyball games on a small scale, increasing the promotion of volleyball, and enhancing the influence of volleyball among university students should be applied in order to make the students understand the advantages of volleyball and actively participate in. Strengthening the usage of stadiums and teacher resources, enhancing the activeness of teachers joining in after school instructions, carrying forward the development of volleyball by various ways and modes should also be used. Meanwhile, in volleyball teaching, teachers should lower the difficulties of volleyball learning, and increase interesting practices. For example, soft volleyball, balloon volleyball and so forth.

\section{REFERENCES}

[1] Tencent Sports. "Chinese Women's Volleyball Team Defeated by Japan with 0:3, The First Loss of Yu's Army in the New Season ", http://sports.qq.com/a/20110612/000063.htm

[2] Ma Qiwei, Zhang Liwei, "Athletic Psychology", Education Press of Zhejiang, pp.29 63,1998.

[3] CHEN Li, HU Qi-lin, "Impacts of mass media on university studentspsports life", Journal of Sports Adult Education, vol.23, pp.49 51, October 2007.

[4] Yang Hongzhi, Fan Qinghui, "Discusses On the sporting events to enjoy", Sports Culture Guide No.4, pp. 71-73, Apr 2011.

[5] Zhang Qiuzhen, "Discussion Sports Interest", Journal of ShanXi Finance and conomics University, vol. 29, pp. 268, November 2007. 